\title{
تقويم أداء عضو هيئة التدريسي في جامعة رايهرين اقليم كوردستان /العراق
}

\author{
هلهزار قادر ابر اهيم \\ محمد محي الدين صادق \\ جامعة رايهرين / الكلية التربية الاساسية \\ جامعة صلاح الدين/الكلية التربية
}

hazhar.qadr@raparinuni.org

ملخص البحث

هدف البحث الى تقويم أداء عضو هيئة التدريس في جامعة راثةرين اقليم كوردستان العراق، والتعرف على الفروق الاحصائية وفقاً لمتغير التخصص و اللقب العلمي، من خلال تطبيق مقياس تقويم الاداء والذي تم اعداده من قبل الباحثين التي يتالف من عشرة مجالات و هي (تدريس، اشراف على البحث، تأليف الكتب، نشر البحث، نشاطاط العلمية، نشاطاط الادارية، تقييم البحوث العلمية، مناقثات البحوث در اسات عليا، الحضور في نشاطاط خارجية، اشغال منصب الاداري)، وقد استخرج الخصائص السيكومترية للمقياس، حيث تحقق الصدق الظاهري من خلال عرض المقياس على (16) خبيراً ومحكماً و كذلك استخرج ثبات(0.81)، وقد طبق المقياس على الأفر اد عينة مؤلفة من (60) تدريسي في جامعة راثترين موزعين على (4) كليات بصورة عثو ائية و أثنتت المعالجات الاحصائية ما يلي: 1. مستوى الاداء التدريسي للعينة ككل ضعيفة.

2. توجد فروق في الاداء وفقا لمتغير (اللقب العلمي)، لصالح التدريسي ذو اللقاب العلمية العالية، لاتوجد فروق في الاداء وفقا لمتغير (الاختصاص).

الكلمات الادالة: التقويم ، الاداء ، الاداء التدريس 
يعد أداء أعضاء هيئة التدريس عنصرا مهما في المنظومة الأكاديمية، ولهذا فإن القصور في هذا الأداء يعد أحد التحديات التي تو اجه الجامعات، حيث أثنارت العديد من الدر اسات التي تناولت تقويم أداء أعضاء هيئة التدريس بالجامعات الى وجود قصور في مجالات الأداء المختلفة (التعليم ـ البحث العلمي - خدمة المجتمع - الجوانب الادارية و التنمية المهنية)(موسى و العتيبي، 2011، ص3)، وكما أن اعضاء هيئة التدريس هم الذين يترجمون الخطط و الأهداف في مؤسسات التعليم العالي إلى و اقع ينعكس في أداء خريجيهم مستقبلاً، وما

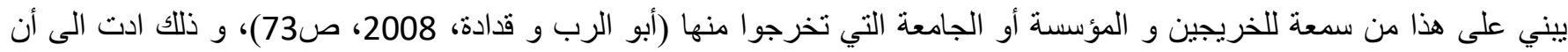
تقويم أعضاء الهيئة التدريسية في الجامعات أمر ا مألوفا في جميع دول العالم المتقدمة و ضرورية في جميع المؤسسات التربوية خاصة الجامعة، لان الجامعة هي اقدم و أرقى مؤسسة التعليم، ولكن من الملحوظ في جامعات كوردستان يتم تقويم التدريسين فقط في مناسبات الترقيات أو في بعض الاحيان في ضمان الجودة ولكن هذا التقويم لايعقبه منابعة لكي يتم تحديد نقاط الضعف و القوة، و اتخاذ الاجر اءات اللازمة مع التدريسي، وهذا يأتي من اعتقاد بأن أعضاء التدريسين ينبغي ألا يتعرضوا للتقييم، و أعطاء الحرية المطلقة لهم أن يقوموا بمهنة التدريس بالطريقة التي يرونها مناسبة، معظم هذه الطر ائق في كوردستان تقليدية، مما جعلت الجامعات في حالة من عدم التطور و حصولها على مرتبة منخفضة في تصنيف الجامعات الداخلية و الدولية.

و لذا تتخلص مشكلة البحث الحالي في التعرف على تقويم اداء عضو الهيئة التدريسية في جامعة راثترين بأقليم كوردستان /

ان تزايد عدد سكان العالم بشكل ملحوظ في الوقت الحالي أدى الى المطالبة و البحث عن العلم بصورة واسعة بين الأجيال في القرن الحالي، وأنعكس ذللك في زيادة عدد الطلبة في الجامعة تحت ضغوط شديدة، مما أحدث انخفاضا ملحوظا في بعض الأحيان في مستويات التعليم الجامعي نتيجة ارتفاع نصيب عضو هيئة التدريس، كما تعددت أنماط أساتذة الجامعات و مصادر إعدادهم، و رغم ذلك قد لا تكون لايهم الكفاءات التدريسية المناسبة لتوصل ما لديهم من معلومات لطلابهم، و للوصول إلى أهداف المطلوبة في التعليم العالي لابد من اجر اء التقويم الدوري و المستمر لأداء العاملين في مؤسسات التعليم العالي(الهويد، 2015، ص2).

ان عضو هيئة التدريس أحد أهم العناصر التي تتظافر للارتقاء بالعملية التدريسية وصو لاً الى التمبيز و جودة المخرجات، وخاصة في ظل التنافس الثديد بين مؤسسات التعليم العالي في هذا الوقت، الذي يشهد ثورة معرفية و تكنولوجية هائلة، وتتوعاً في أساليب التدريس الحديثة باستخدام تكنولوجيا المعلومات و الاتصالات، لذلك أصبح لز اماً على مؤسسات التعليم العالي تهيئة كل الظروف لتحسين أداء عضو هيئة التدريس من خلال عمليات التقويم و التحسين و التطوير التي تمارس بشكل مستمر، الأمر الذي ينعكس إيجابا على المؤسسة التعليمية

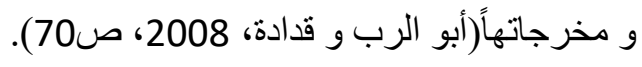

ويعد عضو هيئة التدريس أحد المكونات الرئيسة لمنظومة التعليم العالي لتفعيل هذا الدور، و أنه بناء على مدى تأهيله وقدر اته العلمية و المهنية في أدائه للوظائف الأساسية في هذه المنظومة من تدريس وبحث علمي وخدمة مجتمع تتوقف المكانة و السمعة الأكاديمية للمؤسسة الأكاديمية التي ينتمي لها(السبيعي، 2003، صنية 
فالاساتذة ذوي الخبرة وحدهم من يمتلكون القدرة على معالجة المو اقف المعقدة داخل الفصل(أحمد، 2012، ص759)، كما يحظي الأداء التدريسي لأعضاء هيئة التدريس في مختلف المنظمات التربوية بأهتمام كبير من قبل واضعي السياسات التربوية و الانظمة السياسية في معظم الدول العالم في عصرنا الحالي، وذلك نظرا لأهمية الدور الذي يلعبه عضو هيئة التدريس في الجامعة، لذا تحرص الجامعات على أن تتو افر في أساتذتها الكفايات المألوفة للقيام بهذا الدور، فهي تتوقع من عضو هيئة التدريس فيها أن يكون ذا قدرات، وخصائص متميزة أكاديمياو مهنيا، ماهر ا في التدريس، باحثا متابعا لما يستجد في عالم المعرفة، مثابر ا متحمسا غيور ا على مهنته، عاملا و مشاركا في حل مشكلات مجتمعه، إلى جانب مايتمتع به من صفات إنسانية راقية، وكذلك يتمتع عضو هيئة التدريس الفاعل برؤى تطويرية يؤكد فيها ذاته، ويشجع طلبته على تأكيد ذو اتهم عبر ممارسة التأمل في التعليم، و تعزيز التفاعل بهدف إيجاد تحول نوعي في تعلمه(تيم، 2008، ص3)، و أن تعد وظيفة التدريس الجامعي من أهم الوظائف التي تؤديها الجامعات و أكثر فاعلية في اعداد الطلبة للحياة المستقبلية حيث تزودهم بالمعارف التخصصية و الاتجاهات السلوكية الايجابية و القيمية و كل المهارات، لذلك ثقويم الأداء التدريسي لعضو هيئة التدريسي مهمة في تحقيق أهداف الجامعة و تحديدا عملية إعداد و بناء مخرجات مؤهلة كفو عة تلبي حاجات المجتمع و متطلباته المختلفة(أحمد، 2012، صورئ

و يعد التقويم ضرورة علمية في الوقت الراهن، ييني على أسس علمية كجزء عضوي من نسيج العلمية التعليمية التعلمية، يتم من خلال الوقوف على ما تحقق من أهدافها، و من خلالها يمكن معرفة مدى و مستوى نجاح أو فنشل العملية التعليمية، و ذلك بهدف إصلاح

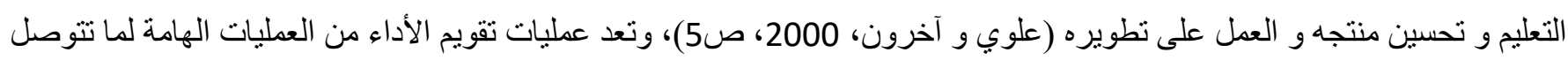
إليه من معلومات وبيانات عن أداء المؤسسة بكاملها، و هذا يتيح لها فرصة تلمس نقاط القوة و الضعف في أي عمل ويمكنها من إعادة النظر

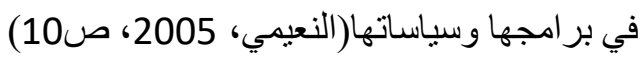

ولعل تقويم أداء عضو هيئة التدريس من أهم المجالات التي ينبغي الاهتمام بها، لما له من أهمية في تحسين الأداء و زيادة فاعليته، و في تطوير المادة العلمية و محتوياتهاو مضامينهاو الأساليب المعتمدة في تدريسها، و هو الوسيلة الوحيدة للتحقق من أن الأداء يتم على التى النحو المحقق لغرضاه(الهويد، 2015، ص2)، كما يسهم تقويم الأداء التدريس في تحسين أدائه الفردي و تطويره، زيادة فاعليتها، و التنبو ؛ بمستوى العمل الذي يمكن أن يؤديه في المستقبل(عبدالكبير و الآخرون، 2011، ص24)، و كذللك يرى (ميللر، 1987) أن عملية تقويم الأداء التدريسي لعضد هيئة التدريس الجامعي تعد من أهم المجالات، التي ينبخي الاهتمام بها لما لها من أهمية في تحسين مستوى الأداء،

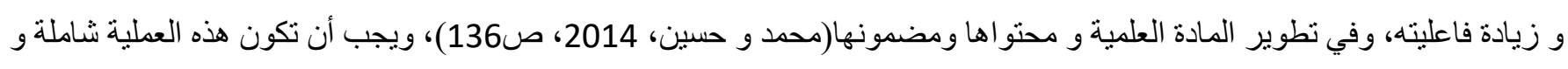

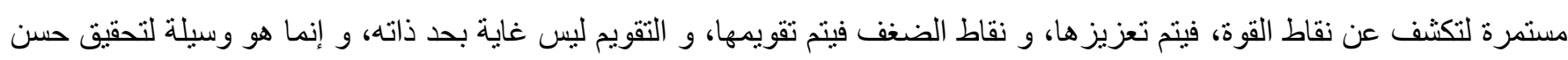

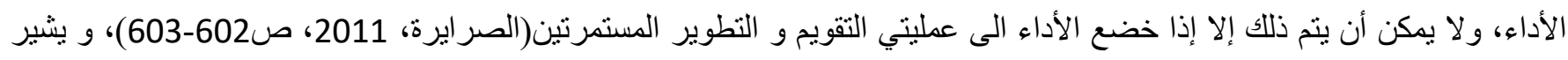
الادبيات بأن التقويم لأداء أعضاء هئية التدريس الغايته الاساسية على التطوير الذاتي المستمر للوصول إلى أعلى المستويات في أداء مهامهم في التدريس و البحث العلمي و خدمة الجامعة او المجتمع، فالتقويم السنوي يعمل على تزويد عضو هيئة التدريس بمعلومات عن لهن مستوى إنجاز في ضوء المهام الموكولة إليه و الأهداف المطلوب تحقيقها (الصرايرة، 2011، ص610).

و أشارت (الجنابي، 2009) الى أن تقويم الأداء لعضوء هيئة التدريس الجامعي يفيد في تطوير مستوى التنريس و رفع كفاءته في الجامعة و الاعتر اف بالتميز في التدريس و التقدير الايجابي للمتميزين من اللأساتذة و تعزيز التدريس رفيع المستوى و الارتقاعبه و إظهار التزام أعضاء هيئة التدريس داخل الجامعة و خارجها، و تشجيع الربط بين مهمة التدريس و المهام الأخرى في البحث العلمي و نعريز 
خدمة المجتمع، كما يمكن الاستفادة من نتائج التقويم في تصميم بر امج التعليم المختلفة و في أخذ العديد من القرارات المتعلقة بالحوافز و

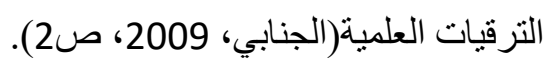

و يرى (عزيز، 2012) أن تقويم في الجامعة في الوقت الحالي أصبح ضرورة حتمية اليوم و الذي بدوره يعتمد على تقويم كفاءة الأستاذ الجامعي المنوط به إعداد الكو ادر البشرية التي تنهض بمسيرة التنمية في المجتمع و تساهم فيها بشكل فعال، ومن أهم المؤشرات على كفاءة الأستاذ الجامعي هو لأداء التدريسي الذي يقوم به(عزيز، 2012، ص105). إن تحقيق الأداء التدريسي المميز يعتمد على فاعلية أداء التدريسي في التخطيط و تتفيذ، و في هذا الخصوص، أكد كل من (بوراسي و دريفر) أن الاداء التدريسي المميز للتدريسي ينطلب منه التخطيط الفعّال للتدريس، الامر الذي يسهم في اعداد الطلبة الجيد

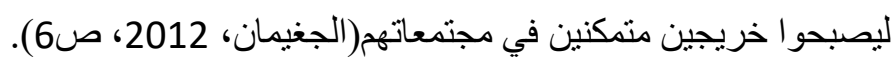

أهداف البحث

1. تقويم مستوى الاداء لعضو الهيئة التدريسية في جامعة راثترين أقليم كوردستان/ العراق

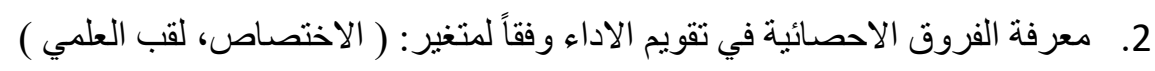

حدود البحث

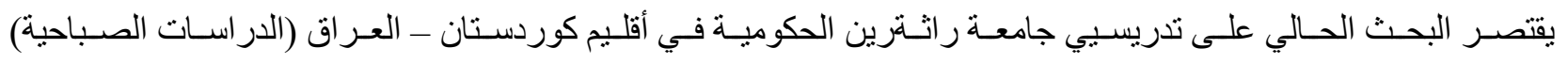
و المستمرين في الدوام للسنة 2016- 2017.

تحديا المصطلحات

1- 1 - 1 - تقويم

- - عرفه بلوم و آخرون (Bloom, et al,1972) إصدار حكم لغرض ما، على قيمة الأفكار و الموضو عات و الأعمال و الطريق

$$
\text { و يتضمن استخدام محكات و معايير كمية(جر ادات، 2004، صأ11). }
$$

- عرفه علام (2000) بأنه عملية منهجية تتطلب جمع بيانات موضوعية ومعلومات صادقة من مصادر متعددة باستخدام أدوت

$$
\text { قياس منتو عة في ضوء أهداف محددة بغرض التوصل الى تقديرات وقرار ات مناسبة(علام، 2000، ص30) }
$$

- عرفه خوالدة (2012) الأسلوب العلمي الذي يتم خلاله تلخيص دقيق للعملية التعليمية و تعديل مسارها(خوالدة، 2012،

.25

(الاد|ء

- عرفه هندرسون (Henderson, 1984) بأنه الجهد الذي يقوم به الثخص لإنجاز عمل ما بالفعل حسب قدرته واستطاعته

$$
\text { (النعيمي، 2005، ص19). }
$$


- عرفه اللقاني و الجمل (1999) أنه كل ما يصدر عن الفرد من سلوك لفظي أو مهاري، وهو يستند إلى خلفية معرفية ووجدانية معينة، و هذا الأداء يكون عادة على مستوى معين، يظهر منه قدرته أو عدم قدرته على أداء عمل ما(اللقاني و الجمل، 1999، ص29) - عرفه القيسي (2006) أنه الطريقة أو الآلية التي يعمل بها الفرد لإنجاز شيء ما(القيسي، 2006، ص46). - عرفه الحباشنة (2013) إنجاز الفرد للمهمات الموكولة إلية ، ويرتبط هذا الإنجاز ، أو الأداء بمدى اكتساب الفرد للمهارات المختلفة التي تلزم لتحقيق هذا الإنجاز (الحباشنة ، 2013، صعاده). 3- تقويم الاداء - عرفه (العجيلي 2001 ) العملية التي يتم من خلالها تحديد كفايات التدريسي، و مدى إسهامهم في إنجاز المهام الموكلة إليهم(العجيلي، 2001، ص85) - عرفه عيد (2005) يقصد به إصدار الحكم على سلوكيات المعلم وما يقوم به داخل الفصل من حيث إدارته للفصل واستخدامه لأساليب التقويم وكفايات الثرح و التدريس المتوفرة فيه، وقدرته على طرح الاسئلة والمناقشة داخل الفصل.(عيد، 2005 . - - عرفه الهويد (2013) العملية المنظمة التي تقارن الأداء الفعلي للفرد بالأداء المستهدف، وتحدد نواحي الضعف والقوة في الأداء، وتبين أسبابها ثم التغذية المرتدة لتنمية التقويم لكل من الفرد و إدارة الموارد البشرية، وذلك للتأكد من مدى مساهمة إدارة

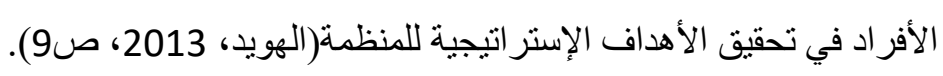

التعريف النظري: عبارة عن قياس السلوك التدريسي، وهذا الأسلوب يركز على ما يفعلةُ في الواقع مححداً نواحي الضعف و القوة، أو أي فعالية وأنشطة مساعدة تستخدمه في أداء العملية التعليمية. التعريف الاجرائي: أنها الدرجة التي يحصل عليها تدريسي الجامعة عند اجابتهم على المقياس المعّد لذلك. 4- عضو هيئة التذريسية: ذلك الثخص الذي يمارس مهنة التدريس في الجامعة من حملة شهادة الدكتور اه أو الماجستير ويساهم في تحقيق أهداف الجامعة(محمد و حسين، 2014، ص136). الاطار النظري والار اسات السابقة أولا: الاطار النظري 1- تقويم الاداء

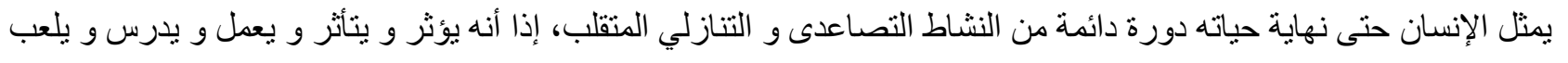

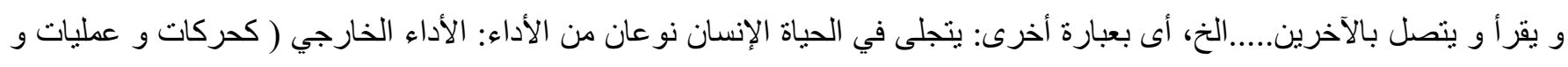
نشاط تفكيري)، و الآداء الداخلي ( كالنشاط النفسي مثل التفكير و الذاكرة و التخيل.....الخ)، بمعنى لآخر أن الاداء كل الانسان له جانبان: جانب قابل للملاحظة المباثرة، و آخر قابل للملاحظة غير المباثر، ومع هذا فإنن هذا التقسيم للأداء إلى خارجي و داخلي هؤ تقسيم 
افتر اضي، فأي أداء يقوم به الانسان سواء كان داخلياً أو خارجياً، ير تبط دائماً بتعبييرات خارجيية له (إيماءات)، بمكن تعريف الأداء إجر ائيا عبارة عن نشاط الإنسان الهادف لإنجاز الأهداف المنشودة عن وعي منه لإشباع حاجاته و اهتمامانه الخاصة به و المتعلقة بمحيط

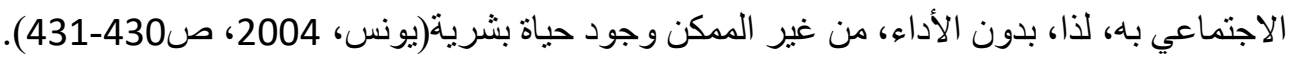

و الاداء التدريس هو سلوك الذي يقوم به المدرس أثناء مو اقف للتدريس سواء دخل المحاضرة أو خارجه، و يلاحظ أن هذا الأداء هو الترجمة الإجر ائية لما يقوم بة المدرس من أفعال أو استراتيجية في التدريس أو في إدارته للفصل أو مساهمته في الأنشطة الجامعية أو غيرها من أعمال أو الأفعال، التي يمكن أن تسهم في تحقيق تقدم في تعلم الطلاب(شحاتة و لآخرون، 2003، صال29) و التقويم الأداء القائم على الأداء المعقد، و هو نوع من التقويم الدينامي أو النمائي لأداء المتعلم مع الوقت، وهو أيضاً ينتمي الى التقويم الواقعي: حيث يعتمد هذا النوع من التقويم على أنواع خاصة من الاختبار ات، مثل اختبارات: مهام الأداء الأكاديمي Academic performance tasks و المهام المرتبطة بالو اقع Authentic tasks، وخلال السنوات الأخيرة زادت المطالبة بضرورة تجريب وسائل وأساليب التقويم القائم على الأداء كنوع من التقويم الو اقعي (الحقيقي)، وجاء الاهتمام بتقويم الأداء كرد فعل مباشر للانتقادات الحادة التي وجهت إلى الاختبارات الاخرى التقليدية المعتادة، والتي لاتقيس في الغالب سوى العمليات العقلية بأدنى مستوياتها(شحاتة و لآخرون، 2003،

يصنف التقويم وفق الغرض الذي يسعى لتحقيقه وفق الأنماط النالية :

أـ التقويم المبدئي (التشخيصي): يستخدم في بداية سنة الدر اسية أو برنامج محدد و ذلك بهدف التعرف على الخبرات السابقة التي يمتلكها المتعلم و نحتاجها للبناء عليهاو كذللك تحديد فاعلية عملية التعليم و التعلم في ضوؤ مقارنة الأداء القبلي و البعدي. بـ التقويم التكويني: وهي العملية المصاحبة لعملية التعليم و التعلم و تهدف لتزويد المتعلم بتغذية راجعة تحسينية و مستمرة تصوب المسار أو لا بأول.

تــ التقويم الختامي: ويستخدم في نهاية مقرر أو نهاية وحدة تدريسية بهدف التأكد من مدى تحقق الأهداف و قياس نواتج التعلم. ثـ التقويم التتبعي: ويجري هذا التقويم بعد الانتهاء من تتفيذ المنهاج أو البرنامج و بعد فترة من التقويم النهائي من أجل معرفة الآثار

$$
\begin{aligned}
& \text { البعدية له سلامة، 2013، ص37). } \\
& \text { خصائص تقويم الاداء : }
\end{aligned}
$$

يتــميز التقويــم الاداء عـن التقويم التقليدي بعدة خصائص(الدوسري، 2004) ومن أهم هذه الخصائص:

أ. التقويم الأداء مباثر في طبيعته، يقيم المهام المعرفية و الفكرية المعقدة (Complex Cognitive tasks) كما هي في واقع الحياة، أو يحاكيها simulation كما هي في الواقع، و ذللك خلافا للتقويم التقليدي. ب. يركز التقويم الأداء على العملية و الناتج Process and Product وليس على النناتج فقط. ت. يتميز التقويم الأداء بالتكامل و الفهم من جهة و التطبيق من جهة أخرى. ث. يقوم الفرد في التقويم الأداء بعملية التقويم الذاتي للمشروع أو العمل أو المهمة التي أنجز ها. 
ج. يستمد التقويم الأداء مصداقيته Credibility و صدقه validity من طبيعة الأداء الأصيل authentic للمهمة التي ينفذها الفرد و ارتباطها بو اقع الحياة وما تتضمنه منن أعمال فكريـة و الأداءو إنتاج يرتبط بسـلامة الحكم و صدق عو اقب(نتائج)

ح. يعتمد التقويم الأداء على التقدير الكيفي Qualitative و بناءً على سلالم تقدير rating scales و صفية الأداء.(الدوسري، (47-45) 2004) صن

\section{4- طرق تقويم أداء عضو هيئة التدريس الجامعي:}

ويهـف تقويم الأداء التدريسـي إلى تحسـين مستوى أداء عضـو هيئة التدريس بصـفة مستمرة، وتطوير كل مـا يـرتبط بالعمليـة التدريسية سو اء داخل حجرات الدر اسة أو خارجها باستخدام عدة طرق للتقويم وهي:

أ. التقويم عن طريق الطلبة: يقوم الطلبة بتقويم أداء عضو هيئة التذريس، ويستخدم لهذا الغرض بطاقات أو نمـاذج خاصـة لمعرفـة آراء

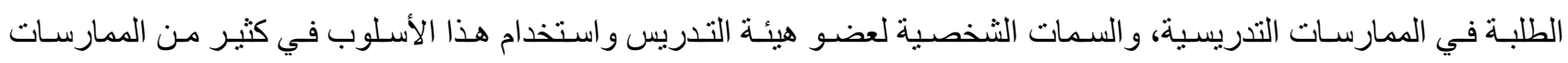
الاكاديمية(المحبوب، 2000، ص247).

ولكن لهذه الطريقة عيوب ويمكن تلخيصها فيما يلي : أشارت بعض الدر اسات بأن الطلبة الذين يعطون درجات مرتفعة لأعضاء هيئة التدريس هم الذين يحصلون على درجـات مرتفعـة

منهم (Theal \& Franklin, 1990, p291)

إن طلبة الجامعة ليس لديهم الخبرة الكافية و الموضو عية اللازمة التي تمكنهم من تقويم الأداء التدريسي فعند تقويمهم لأعضاء هيئة التدريس يركزون على الصفات و السمات الثخصية لعضو هيئة التدريس أكثر من النواحي العلمية و المهار ات التدريسية.

يرى بعض الباحثين أمثال راسكن(Raskin) أن تقويم الطلبة لعضو هيئة التدريس غالباً ما يؤدي إلى زعزعة الثقة في عضو هيئة التدريس و التقليل من مكانته في الجامعـة (Raskin, 1979, p382). كمـا يؤكد سيلدن، بأن طلبـة الجامعـة ليسوا مؤهلين للحكم على (Selden, المستوى العلمي لعضو هيئة التدريس، و أنه من الخطأ الاعتماد على الطلبة عند تقويم هذه الجوانب في عضو هيئة التدريس

بينما يرى المؤيدون لهذه الطريقة، بانها ينو افر فيها الصدق والثبات لأن الطلبة أكثر قرباً لأساتذتهم، ولقد أوضحت دراسـة مور اي و آخرون (Murray \& Other, 1996)، أن تقويم الطلبة لعضو هيئة التدريس يؤثر إيجابياً في تحسين الفعاليات التدريسية، كمـا أثنارت در اسة (Schmelkin) إلى قلة معارضة أعضاء هيئة التدريس لطريقة تقويم الطلبة لهم (Schmelkin and others, 1997, p584).

ب. التقويم الذاتي: يعتبر التقويم الذاتي أسلوب من أسـاليب التقويم التي تتبعها كثثر من الجامعات، ويقصد بـه أن يتولى عضو هيئة

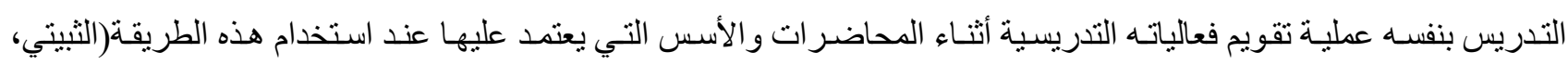
1996، ص28)، إذ يقوم عضو هيئة التدريس بنفسه لجمع معلومات عن أدائه التدريسي ومحاولة الاستفادة منها في تطوير نفسه وقد

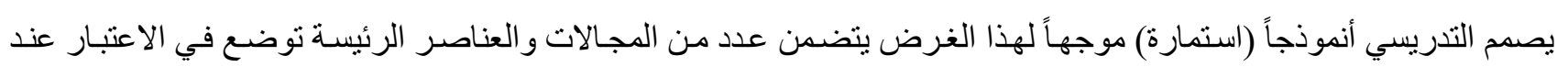


إجر اء عملية التقويم الذاتي لأدائه(Haskell, 1997, p286). ولقد وجد سيلدن (Selden,1988) أن هناك تز ايد في استخدام هذا الأسلوب، حيث ارتفعت نسبة عمداء الكليات الذين طبقو هذا النظام من (36\% )عام (1979) (إلى (42\% )عام (1984). أما عن مميز ات التقويم الذاتي، فيرى (شحاته و المزروع) أن التقويم الذاتي يسهم في تتمية أعضاء هيئة التدريس تتميـة شـاملة ليس من النو احي المهنية و الأكاديمية و المهار ات فحسب بـل ينمى جو انب أخرى منها الأحسـاس بالمسؤلية، الثخصية وتعميق القيم الروحية،

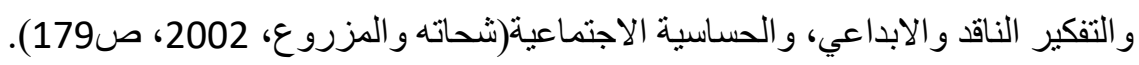

أما عن عيوب طريقة التقويم الذاتي لعضو هيئة التدريس فأنهم يميلون لإعطاء أنفسهم تقدير ات أعلى من التقديرات التي يعطيها

لهم الطلبة(عبدالرزاق، 2007)، وكذلك لا يمكن لهذه الطريقة أن تستخدم في نرقية أعضاء هيئة التدريس (Centra, 1980, p47-49). ج. تقويم الزملاء: وفيه يقوم أعضاء هيئة التدريس بتقويم زملائهم بشكل فردي أو عن طريق تشكيل لجان، وفي كثبر من الجامعات في ألي العالم العربي نجد أن أعضاء هيئة التدريس في الكليات و الأقسام المختلفة يقومون أداء زملائهم من أعضاء هيئة التدريس الآخرين في مجال البحث العلمي، وخدمة الجامعة و المجتمع، وذلك من خلال لجـان الترقيات التي يتشكلها الجامعات حيث تقوم هذه اللجـان بتقويم الجوانب الكمية و النو عية لأبحاث أعضاء هيئة التدريس ونشاطه العلمي، كذللك مسـاهمته في مجال خدمـة الجامعة و المجتمع

$$
\text { (عبدالرزاق،2007، ص207). }
$$

ويرى المؤيدون لهذه الطريقة أمثال(Seldon, 1980)، إن زملاء العمل لكونهم متخصصين في نفس المهنة فهم اقدر على تقويم زملائهم من أعضاء هيئة التدريس في عدة جوانبها وهي: المعرفة العلمية في مجال الحقيقي، مدى ملائمة أهداف ومحتوى المقرر لأهداف البرنامج و القسم، طريقة تنظيم الموضو عات، الطرق المستخدمة في تقويم التلاميذ(Selden, 1988, p195) ويرى مؤيدوا هذا الأسلوب أفي أن أفضل من يقوم بهذه المهمة هم زملاء المهنة بحكم معرفتهم بالمادة العلمية و إلحاقهم بالأهداف و القراءات وطر ائق التدريس المناسبة للموضوع (الثبيتي و القرني، 1993، صنوم 443) ،ولكن يعاب على طريقة تقويم الزملاء لعضو هيئة التدريس وخاصة أسلوب الزيارات بأن نتائجه غير موضو عية وتتأثر بالمجاملة و الصداقات الثخصية (Cole, 1982, p21)

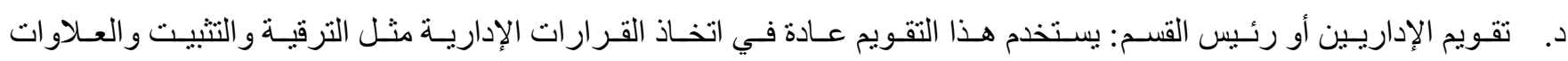
(Cole,1982) (الثرى الثبيتي بأنه يستخدم في الترقية والتثبيت الوظيفي وتجديد عقود العمل (الثبيتي، 1996، 34) ويرى كل من سيلدن وشميلكين (Schmelkin \& others, 1997,selden, 1988) بـأن تقويم رئيس القسم يأتي في المرتبـة الأولى من بين أساليب التقويم. ومن المعروف أن رؤساء الأقسام يلعبون دوراً هاماً في عملية تقويم التدريس الاكاديمي، وذلك من خلال اطلاعهم المباثر على الأعباء التدريسية لأعضاء هيئة التدريس في القسم وتوصيف المقررات الدراسية، واعداد الطلبة في الثـب، كل هذا

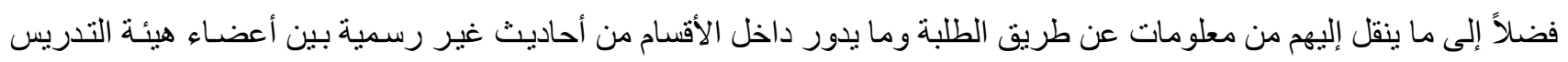
عن بعضهم البعض وكذلك يعتمد رؤساء الأقسام عند تقويمهم للأداء التدريسي إلى مصادر أخرى مثل تقويم الطلبة وتقويم الزملاء و التقويم الذاتي ، وكلها مصادر توفر لهم من المعلومات مما يمكنهم من تقويم الفعاليات التدريسية في القسم بشكل جيد (عبد الرزاق،

.247)، ص2007

ثانياً : الدراسات السابقة 
- در اسة الكندري و ابر اهيم 1990: هدف البحث الى تفسير بيانات و مؤشرات مهمة عن مستويات النشاط الأكاديمي لاى أعضاء هيئة التدريس بجامعة الكويت، و مقارنة هذا النشاط بين المجموعات المختلفة من أعضاء هيئة التدريس ، وتحديد الأنشطة المهمة لهم، ومدى تباين هذه الأنشطة بالنسبة لهم و درجة أفضليتها و اهتمامهم بها ، تم بناء استبانة اشتملت على بيانات أولية و أسئلة لتقدير الوقت المخصص للأنشطة المتعلقة بالعبء التدريسي وأسئلة لتقدير الوقت المخصص لأنشطة البحث العلمي و أسئلة لتقدير الوقت ولت ولته المنصرف في خدمة الجامعة و المجتمع و نشاطات أخرى، وتم تطبيق الاستبانة على (204) أعضاء هيئة التدريس، و توصلت نتائج الى ان النشاط الاكاديمي لعضو هيئة التدريس في جامعة الكويت ينحصر في (التدريس و البحث العلمي و خدمة الجامعة و المجتمع). - ـ در اسة محمد و حسين 2014: هدف البحث الي التعرف على مستوى الأداء التدريسي لأعضاء هيئة التدريس من وجهة نظر الطلبة، و ذلك بنطبيق استبيان على عينة مكونة من (184) طالباً و طالبة، ونم استخدام برنامج الحقيبة الإحصائية للعلوم الاجتماعية، و ظهرت النتائج أن مستوى الاداء التدريسي لأعضاء هئية التدريس عالٍ، و تبين وجود فروق دالة في الاداء التدريسي من وجهة نظر الطلبة يعزى لمتغير ات العمر و الصف و الخلفية الدر اسية، و لم تظهر فروق دالة تبعا لمتغير الجنس.

\section{منهجية البحث وإجراءاته}

منهج البحث: في ضوء طبيعة الدر اسة و الأهداف التي تسعى إلى تحقيقها تم استخدام المنهج الوصفي، حتى يتمكن من خلاله التعرف على تقويم أداء عضو هيئة التدريس لدى التدريسين الجامعة، و هو أحد أشكال البحوث الثائعة التي اشتخل بها العديد من الباحثين و يعد الأسلوب الوحيد المكن في نظر العديد من الباحثين لدر اسة الكثير من المجالات الإنسانية (ملحم، 2007، صو369).

مجتمع البحث: يقصد به كامل أفر اد أو أحداث أو مشاهدات موضوع البحث (عبيدات و آخرون، 2004، ص84)، و يتكون مجتمع البحث الحالي من التدريسي الجامعة راثةرين للعام 2017-2018 وقد استطاع الباحث من الحصول على افر اد المجتمع من خلال مر اجعته بكتاب رسمي لقسم الاحصاء و التخطيط في الجامعة راثةرين، و كان عدد التدرسين (235) تدريسياً منهم (131) مدرس مساعد و (80) مدرس

$$
\text { و (22) استاذ مساعد و (2) استناذ. }
$$

عينة البحث: هي عبارة عن المجموعة الجزئية من مجتمع البحث يتم اختيار ها بطريقة معينة و إجر اء الدراسة عليهاو من ثم استخدام تلك النتائج و تعميمها على كامل مجتمع الدراسة الأصلي (عبيدات و اخرون، 2004، صه8)، و اختيار العينة يعتبر من الخطوات و المراحل المهمة للبحث، وقد بلغ عدد التدريسي في جامعة راثترين (235) تدريس و بغية اختيار عينة ممثلة لمجتمع البحث قام الباحثان بإختيار عينة البحث بطريقة عشو ائية بسيطة بلغ (60) تدريسي موز عين على (4) كليات، و هذه تشكل بنسبة (0.25) من المجتمع. أداة البحث: لغرض قياس متغير البحث وهو (التقويم الاداء التدريسي)، قاما الباحثان بأعداد الاداة لقياس التقويم الاداء.

مقياس التقويم الاداء التدريسي: من أجل اعداد مقياس ( التقويم الاداء التدريسي ) أطلع الباحثان على الأدبيات و الدراسات السابقة التي تتعلق التقويم الاداء كدراسة ( الصباطي و محمد، 2007 و تيم، 2008 و الجنابي، 2009 و الثوك و العجيل، 2010 و الصرايرة، Fisicaro, 2010 \& Alga, 2013 و عزيز، 2012 و الهويد، 2013 و محمد و حسين، 2014) و بعض الدراسات الاجنبية و مقابلة بعض من خبر اء من مجال التقويم، لم يستطيع الباحثنان الحصول على مقياس يلائم مجتمع البحث 
لتقويم الاداء التدريسي من وجهة نظر هم، ولكن هنالك مقاييس يقيس الاداء من قبل الطلاب أو رؤساء الاقسام او عمداء الكلية أو الزملاء، لذلك قاما الباحثان باعداد المقياس، و استعانا ببعض المقاييس في تحديد مجالات البحث حيث وضع (10) مجالات، و من أجل اعطاء درجات لهذه المجالات أستعانا بر أي مجموعة من خبر اء (الملحق2) و بذلك أصبح المقياس جاهزاً بصورته الأولية لحساب الخصائص السايكومترية (ملحق 1).

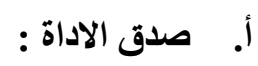

الصدق الظاهري :يعد الصدق من الخصائص المهمة التي يجب الأهتمام بها عند إجر اء البحث و من العوامل المهمة التي يجب ان يتأكد منها الباحث عند وضع أو تصميم استبانة بحثه، و أن أداة البحث تعتبر صادقة عندما تقيس ما افترض ان تقيسه (ابر اهيم، 2000، ص43)، و لغرض التأكد من صدق المقياس قاما الباحثان بعرض فقرات المقياس بصيغتها الاولية و المكونة من (10) مجالات (الملحق1)، على مجموعة من المحكمين المختصين في التربية و علم النفس (الملحق2) و ذلك للتأكد من صلاحية مجالات لتقويم الاداء التدريسي، بعد جمع استبيانات لم يتم أي تغيير في مجالات مقياس. ب. ثبات الأداة: يعرف الثبات بأنه الاتساق في النتائج (ابر اهيم، 2000، ص42) و يتصف الاختبار الجيد بالثبات و الاختبار الثابت هو

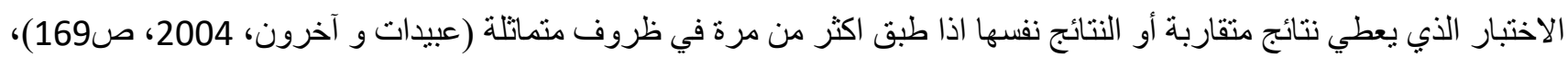
لهذا الغرض قام الباحثان بنوزيع المقياس على عينة من التدريسي بلغ عددها (30) التدريس في جامعة راثترين و بصورة عشو ائية، و تم استخر اج معامل الاتساق الداخلي باستخدام معامل الفاـ كرونباخ وقد بلغ معامل ثبات ألفاء كرونباخ لمقياس (0.81). تطبيق أداة البحث: طبق مقياس البحث (التقويم الاداء) على عينة من التدريسيين، وعند توزيع المقياس على أفراد العينة قام الباحثان بتوضيح التعليمات العامة عن البحث فيما يتعلق بأهمية البحث و ضرورة الاجابة عن كل مجال من مجالات المقياس بشكل صريح و دقيق

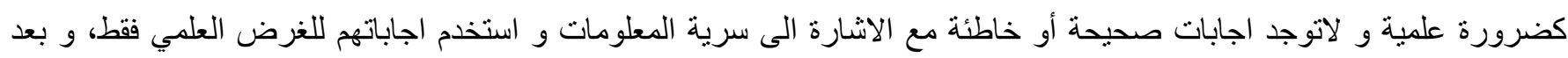
الانتهاء من التطبيق تم تفريغ البيانات و استغرقت عملية التطبيق مايقارب اسبو عين.

الوسائل الإحصائية: نم إستخدام الحقيبة الاحصائية للعلوم الاجتماعية (SPSS) لاستخر اج المؤشرات الاحصائية و تحليل البيانات للمقاييس المستخدمة في البحث الحالي و الوسائل الاحصائية المستخدمة هي :

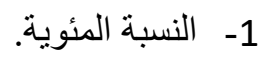
2- معادلة الفا كرونباخ. 3- مربع كاي

\section{عرض النتائج ومناقشتهها}

بعد تحليل البيانات على وفق الحقيبة الاحصائية للعلوم الاجتماعية (SPSS) و تبعاً لأهداف البحث، سيتم عرض النتائج و 
من جل تحقيق هذا الهدف قام الباحثان بتحليل الاجابات و بجمع الدرجات التي حصل عليها المستجبين على المقياس و مقارنتها بمستويات التي حدد في المقياس و استخر اج نسبة المؤية لتدريسين وقد تبين أن نسبة (73.3\%) من التدريسيين كانت درجاتهم تحت (65) درجة ضمن المقياس بمعنى أخر كانت أدائهم ضعيفة و نسبة (26.7\%) منهم كانت درجاتهم ترواحت بين (66 - 131)، و عند مقارنته بمعيار المقياس كان ادائهم متوسطا، و لايوجد أي من تدريسين يكون درجاته أعلى من (131)، و الجدول (1) يوضح ذلك .

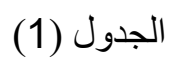

$$
\text { نتائج نسبة مؤية للادداء التدريس }
$$

\begin{tabular}{|c|c|c|}
\hline نسبة من مجموع الكلي & عدد التدريسي & مستويات \\
\hline$\% 73.3$ & 44 & ضعيف (0 - 65) \\
\hline$\% 26.7$ & 16 & متوسط (66 - 130) \\
\hline$\% 0$ & 0 & عالي (131 - فأكثر) \\
\hline
\end{tabular}

و تبين في الجدول أعلاه أن أداء التدريسيين على اغلب كان ضعيفاً، و يعتقد الباحثان بأن هذه النتيجة تتلائم مع واقع الحياة لأن التغييرات التي حدثت في أقليم كوردستان ـ العراق أدت الى عدم الاستقرار الأمني و الاقتصادي و كذلك عدم نوفر الدورات التطويرية الكافية للتدريسيين وضعف حالات التشجيع و صرف المكافأت لهم في انجاز البحوث و تأليف الكتب مما أدى الى تراجع الأداء التدريسي في الجامعة.

\section{الهُف الثاني: معرفة الفروق الاحصائية في تقويم الاداء وفقاً لمتغير: (الاختصاص، لقب العلمي).}

أ. الاختصاص (العلمي، الاتساني): و من أجل التحقق من هذا الهدف و حساب الفروق بحسب الاختصاص في الاداء، استخدم الباحثان نسبة المؤية في الاداء لكلا الاختصاص، بما أن عدد المدريسين من الاختصاص العلمي كانت عددهم (19)، و عدد الانساني (41)، ظهرت نتائج أن نسبة (31.7\%) من التدريسي الاختصاص الانساني أدائهم ضعيفة و نسبة(68.3\%) ادائهم متوسطة أما بنسبة الاختصاص العلمي نسبة(15.8\%)كانت الادائهم ضعيفة و نسبة(84.2\%)منهم الادائهم منوسط من مجتمع التدريسي الاختصاص

$$
\text { العلمي، و جدول (2) يوضح ذللك. }
$$

\begin{tabular}{|c|c|c|c|c|}
\hline \multicolumn{3}{|c|}{ مستويات } & \multirow[t]{2}{*}{ عدد } & \multirow[t]{2}{*}{ المجمو عة } \\
\hline 131 ـ عالي 131 & متوسط & ضعيف 0 & & \\
\hline
\end{tabular}

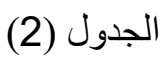

عرض فروق في الاداء بحسب الاختصاص 


\begin{tabular}{|c|c|c|c|c|}
\hline & 130 & & & \\
\hline$\% 0$ & $\% 84.2$ & $\% 15.8$ & 19 & \\
\hline$\% 0$ & $\% 68.3$ & $\% 31.7$ & 41 & \%030 \\
\hline
\end{tabular}

و لأجل استخر اج الفروق الاحصائية بين التدريسيين وفقا لمتغير الاختصاص تم استخدام مربع كاي ظهر بأن القيمة مربع كاي المحسوبة (2.155) بدرجة حرية (1)، و هي غير ذات دلالة إحصائية عند مسنوى دلالة (0.05) مما يثير لايوجد فرق في اداء وفقا لمتغير الاختصاص. ب. اللقب العلمي: و من أجل التحقق من هذا الهدف و حساب الفروق وفقا الي اللقب العلمي، استخدم الباحثان نسبة مؤية في الاداء بتدرج لقب العلمي، بما أن عدد المدريسيين ذو لقب (مساعد مدرس) كان عددهم (30)، و عدد (مدرسين) كان (24)، و عدد (استاذ المساعد) كانت (6)، و عدد (استاذ) كان (0) بمعنى الاخر لايوجد اي مستجبين من ذو اللقاب استاذ، ظهرت نتائج أن نسبة (90\%) من التدريسي اللقاب مساعد المدرس أدائهم ضعيفة و نسبة(10\%) ادائهم متوسطة، أما بنسبة اللقاب مدرس نسبة(08.34\%)كانت الادائهم ضعيفة و نسبة(41.66\%)منهم الادائهم منوسط، و نسبة (33.34\%) من التدريسي اللقاب استاذ مساعد أدائهم ضعيفة و نسبة(66.66\%) ادائهم متوسطة، و جدول (3) يوضح ذللك. (3) (3) (3) (2) (2)

عرض فروق في الاداء بحسب اللقاب العلمية

\begin{tabular}{|c|c|c|c|c|}
\hline \multicolumn{3}{|c|}{ مستويات } & \multirow[t]{2}{*}{ عدد } & \multirow[t]{2}{*}{ المجمو عة } \\
\hline 131 ع عالي فاكثر & $\begin{array}{c}\text { متوسط } 66 \text { - } 130 \\
\text { من }\end{array}$ & ضعيف 0 & & \\
\hline 0 & $\% 10$ & $\% 90$ & 30 & المساعد مدرس \\
\hline 0 & $\% 41.66$ & $\% 58.34$ & 24 & مدرس \\
\hline 0 & $\% 66,66$ & $\% 33.34$ & 6 & استاذ المساعد \\
\hline
\end{tabular}

و لأجل استخراج الفروق الاحصائية بين التدريسيين وفقا لمتغير اللقب تم استخدام مربع كاي ظهر بأن القيمة مربع كاي المحسوبة (11.409) بدرجة حرية (2)، و هي ذات دلالة إحصائية عند مستوى (0,05) مما يشير أن التدريسي ذو اللقاب العلمية استاذ المساعد اكثر نشاطاو ادائهم مرتفعا من التنديسي الذين اللقابهم ادنى منهم.

و يعتقد الباحثان بأن هذه النتيجة التي تشير الى أن التدريسين كلما يرتفع ألقابهم يكونون اكثر نشاطا، و حيوية و يسعون الى بذل

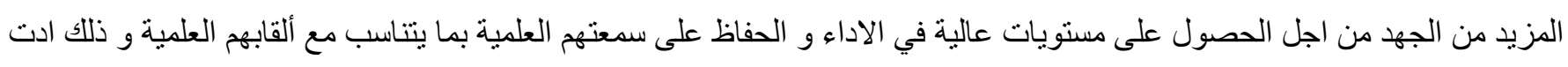
الى ارتفاعهم في اللقابهم العلمية. 


$$
\text { على وفق نتائج البحث الحالي يوصي الباحثان بمايأتي : }
$$

$$
\text { 1- أن تهنم الجامعات بمتابعة التدريسي و اعطاء المكافأت و الثواب للذين يكون الاداءهم عالي. }
$$

2- ان تهتم ادارة الجامعات بعقد الندوات و المؤتمرات و السمينار ات و لاسيما للتدريسيين الذين مستويات اداءهم ضعيفة.

$$
\text { 3- إيفاد وزارة التعليم العالي للتنريسيين الذين الادائهم عالي الى دورات خارج الوطن. }
$$

4- توفير وزارة التعليم العالي فرص منح در اسية في الجامعات العالمية للتدريسين الذين الادائم ممتاز.

5- أن تراعي الدولة الظروف الحياتية و المعاثية للدريسيين من أجل رفع مستوياتهم العلمية و الوصول بهم الى رضا العمل و

على وفق النتائج ، يقترح الباحثان إجر اء الدر اسات الاتية من قبل الباحثين مستقبلاً و كما يأتي :

$$
\begin{aligned}
& \text { 1- إجر اء در اسة عن العلاقة بين الاداء التدريسي وبعض المتغيرات (سنوات الخدمة و اللقب). } \\
& \text { 2- إجر اء در اسة مقارنة تقويم الاداء التدريسي لدى رؤساء الاقسام و التدريسيين أنفسم. } \\
& \text { 3- إجر اء دراسة عن لاداء التدريسي و علاقته بالرضا عن العمل و جودة الحياة. }
\end{aligned}
$$

المصادر

1. ابر اهيم، مروان عبدالمجيد(2000) أسس البحث العلمي لإعداد الرسائل الجامعية، ط1، مؤسسة الوراق، عمان. 2. أبو الرب، عماد و قدادة، عيسى(2008) تقويم جودة أداء أعضاء هيئة التدريس في مؤسسات التعليم العالي، المجلة العربية

$$
\text { لضمان جودة التعليم العالي، العدد (1) } 2008 .
$$

3. أحمد، أحمد ابر اهيم(2012) دراسة تقويمية لأداء الأستاذ الجامعي والمادة التدريسية من وجهة نظر الطالب الجامعي: المؤتمر

$$
\text { العربي الدولي الثاني لضمان جودة التعليم العالي. }
$$

4. تيم، حسن(2008) آر اء طلبة الدراسات العليا في الأداء التدريسي لأعضاء هيئة التدريس في كلية الدر اسات العليا بجامعة النجاح الوطنية. 5. الثيتي، مليحان و القرني، علي(1993) طرق وأساليب تقويم أداء أعضاء هيئة التدريس في الجامعات السعودية، مجلة جامعة

$$
\text { الملك سعود العلوم التربوية، } 5 \text { (2). }
$$

6. جر ادات، عدنان محمد مصطفى(2004) تقويم أسلوب الاستقصاء و التقويم التشخيصي و أثز هما في التفكير الابداعي والتحصيل لدى طلبة التعليم الأساسي في الاردن، اطروحة دكتور اه غير منشورة، كلية التربية، الجامعة المستصرية. 
7. الجنابي، عبدالرزاق شنين(2009) تقويم الأداء التدريسي لأعضاء هيئة التدريس في الاجامعة وانعكاساته في جودة التعليم

$$
\text { العالي، مؤتمر الجودة في الجامعة الكوفة } 2009 .
$$

8. الجيغمان، عبدالله بن محمد(2012) الأداء التدريسي لمعلمي تربية المو هوبين في تتفيذ الأنموذج الإثر ائي في مدارس التعليم العام في المملكة العربية السعودية، مجلة جامعة الملك سعود، العلوم التربوية و الدر اسات الاسلامية 2012.

9. الحباشنة، عدنان خلف(2013) مستوى الأداء التدريسي لمعلمي الرياضيات للصف العاشر الأساسي بمحافظة الكرك من وجهة نظر الطلبة، رسالة ماجستير غير منشورة، جامعة الثرق الأوسط .

10. خو الدة، اكرم صالح محمود(2012) التقويم اللغوي في الكتابة والتفكير التأملي، ط1، عمان، دار الحامد للنشر و التوزيع. 11. الدوسري، ر اشد حماد(2004) القياس و التقويم التربوي الحديث مبادئ وتطبيقات وقضايا معاصرة، ط1، دار فكر، عمان الاردن.

12. السبيعي، خالد بن صالح المرزم(2003) اتجاهات أعضاء هيئة التدريس نحو ممارسة أساليب التدريس الفعالة ومتطلبات استخدامها في جامعات دول مجلس التعاون لدول الخليج العربي، مجلة رسالة الخليج العربي العدد (113). 13. سلامة، جهاد حسن محمود(2013) دور المساءلة في تحسين أداء المعلمين بمدارس وكالة الغوث بغزة من وجهة نظر المديرين وسبل تطويره، رسالة ماجستير غير منشورة، كلية التربية، جامعة الازهر. 14. شحاته، حسن و المزروع، هيا(2002) التقويم الذاتي لأعضاء وقيادات كليات البنات بالمملكة العربية السعودية، مدخل لتطوير الأداء الجامعي، بحث قدم في ندوة تطوير عضو هيئة التدريس، جامعة الملك سعود، مركز الدراسات الجامعية للبنات الأقسام

15. شحاته، حسن و الاخرون(2003) معجم المصطلحات التربوية والنفسية، ط1، القاهرة، الدار المصرية اللبنانية. 16. الصر ايرة، خالد أحمد(2011) الاداء الوظيفي لاى أعضاء الهيئات التدريسية في الجامعات الاردنية الرسمية من وجهة نظر رؤساء الأقسام فيها، مجلة جامعة دمشق - المجلد 27-العدد الاول +الثناني-2011. 17. عبدالرزاق، وفاء(2007) اتجاهات أعضاء هيئة التدريس بكلية التربية بجامعة الملك سعود نحو أساليب وطرق تقويم أدائهم، الجمعية السعودية للعلوم التربوية والنفسية (جستن)، اللقاء السنوي الثالث. 18. عبدالكبير، صالح عبدالله والآخرون(2011) نظام تقويم الأداء المدرسي في مدارس التعليم الأساسي في الجمهورية اليمنية، مركز البحوث و التطوير التربوي /فرع عدن، الجمهورية اليمنية. 19. عبيدات، ذوقان و لاخرون (2004) البحث العلمي مفهومه و أدو اته وأساليبه، ط8، دار فكر للطباعة والنشر و التوزيع، عمان. 20. العجيلي، صباح حسين و آخرون(2001) مبادئ القياس و التقويم التربوي، بغداد، مكتب حمدان الدباغ للطباعة. 21. عزيز، حاتم جاسم(2012) تقويم أداء أعضاء هيأة التدريس في الجامعة من وجهة نظر الطلبة (در اسة ميدانية في جامعة ديالى)،

$$
\text { مجلة الفتح، العدد الخمسون، أب } 2012 .
$$

22. علام، صلاح الدين محمود(2000) القياس و التقويم التربوي و النفسي، اساسياته وتطبيقاته وتوجيهاته المعاصرة، ط1، دار الفكر العربي، القاهرة.

23. علوي، أحمد صالح وآخرون(2011) نظام تقويم الأداء المدرسي في مدارس التعليم الأساسي في الجمهورية اليمنية(دراسة ميدانية)، مركز البحوث و التطوير التربوي، فرع عدن، الجمهورية اليمنية. 
24. عيد، غاده خالد(2005) تقويم اداء معلمي المرحلة الثانوية بدولة الكويت "در اسة مقارنة للتقويم الذاتي، وتقويم الطلاب، وتقويم

$$
\text { 25. القيسي، نايف نزار(2006) المعجم التربوي العلمي"، المجلة التربوية، مجلد } 19 \text { العدد77، الكويت. }
$$

26. اللقاني، أحمد حسين والجمل، على أحمد(1999) معجم المصطلحات التربوية المعروفة في المناهج وطرق التدريس، ط2، عالم

$$
\text { الكتب، القاهرة. }
$$

27. المحبوب، عبد الرحمن إبراهيم(2000) تقويم الأداء التدريسي لأعضاء هيئة التدريس بجامعة الملك فيصل من وجهة طلبة

الجامعة، مجلة جامعة الملك سعود، العلوم التربوية والدر اسات الإسلامية، 12 (2).

28. محمد، احمد قاسم وحسين، جميل أحمد(2014) الأداء التدريسي لأعضاء هيئة التدريس في سكول التربية الرياضية من وجهة

$$
\text { نظر الطلبة في جامعة دهوك، مجلة جامعة للعلوم الانسانية، مجلد18، العدد 5، سنة } 2014 .
$$

29. موسى، فتحي على و العتيبي، منصور بن نايف(2011) نظوير أداء أعضاء هيئة التدريس بجامعة نجران وفقا لمعايير الجودة و

$$
\text { الاعتماد الأكاديمي، مجلة كلية التربية، جامعة الأزهر، العدد145، مارس } 2011 .
$$

30. ملحم، سامي محمد(2007) مناهج البحث في التربية و علم النفس، ط5، دار المسيرة للنشر والتوزيع و الطباعة، عمان.

31. النعيمي، شهرز اد محمد شهاب موسى(2005) بناء برنامج تطويري لمديري المدارس الابتدائية في محافظة نينوى في ضوء

$$
\text { تقويم أدائهم لمهار ات القيادة الإدارية والتربوية، اطروحة دكتو اره غير منشورة، كلية التربية، جامعة الموصل. }
$$

32. الهويد، ندى على سالم(2013) مساهمة تقويم اداء عضو هيئة التدريس في رفع جودة التعليم الجامعي، رسالة ماجستير غير

$$
\text { منشورة، جامعة أم القرى. }
$$

$$
\text { 33. يونس، محمد نبي(2004) مبادئ علم النفس، ط1، دار الثروق للنشر والتوزيع، عمان - الاردن. }
$$

34. Centra, Jonna, A.(1980) Determining faculty effectiveness, san Francisco, jossey - Bass publishers.

35. Cole, C. (1982) Improving Instruction: Issues and Alternatives for Higher Education, AA HE/ Eric, Education Research Report No.4.

36. Hidlebaugh, Everett James(1973) A model for developing a teacher performance evaluation system: a multiple-appraiser approach, lib.dr.iastate.edu/rtd.

37. Haskell, R.E(1997) Academic Freedom, Tenure, and student Evaluation of faculty: Galloping polls In the 21st century. Education policy Analysis Archives, 5(6).

38. Murray \& et. al.(1996) Longitudinal trends in student instructional ratings: does evaluation teaching (report No. HE031120 : paper presented at the annual meeting of the American educational research Association. (ERIC Document reproduction service No. ED 917664). 
39. Raskin- Betty, \& plante, patricia.(1979) the student evaluation of teachers, academe, 65.

40. Schmelkin \& et al.(1997) faculty perspectives on course and teacher evaluation, Research in higher education, 38 (5).

41. Seldin peter.(1988) evaluation college teaching, in R. young and k. eble (eds), college teaching and learning, No. 33 San Francisco Jossey- Bass publishers, P, 305.

42. Theal ,M., \& Franklin , J.(1990) Student ratings of instruction:n Issues for improving practice . jossey - Bass Inc., publishers, san Francisco.

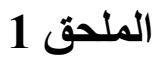

استبانة اراء الخبراء التقويم الاداء 
يروم الباحثان القيام البحث الموسوم " تقويم أداء عضو هيئة التدريس في جامعة رابهرين اقليم كوردستان /العراق" وبعد الاطلاع على الادبيات المتعلقة بالموضوع، أعد الباحثان الاداة التي بين ايديكم لتقويم اداء هيئة التدريس في جامعات اقليم كوردستان و المؤلفة من (10) عشرة مجالا، وبالنظر لما تتمتعون به من دراية و خبرة ميدانية في هذا المجال، يود الباحثان استطلاع ارائكم من خلال تقدير مدى صلاحية كل مجال و درجة المحدة لها او تعديل المجال أو الدرجة التي تحتاج الى ذلك او حذف او اضافة فقرات أو مجالات الآخرى الى لى له الاداة من اجل اغنائها و ابداء أي اقتراحات تجعل اداة التقويم اكثر موضوعية، علما بأن تعريف تقويم أداء التدريس : عبارة عن قياس السلوك التدريسي، وهذا الأسلوب يركز على ما يفعلهُ في الواقع مححداً نواحي الضعف والقوة، أو أي فعالية وأنشطة مساعدة تستخدمه في أداء العملية التعليمية. علما ان التدريسي الذي يحصل على أقل من ( 65 ) يكون ضعيفا في الاداء و الذي يترواح درجاته بين ( 66 - 130 ) درجة يكون ترتيبه منوسطا في الاداء و الذي يكون درجاته من ( 131 ) فأكثر عاليا في الاداء

شاكرين لكم هذا التعاون العلمي.

الباحثنان

$$
\text { م.م. هتذار قادر ابر اهيم }
$$

أ.م.د. محمد محى الدين صادق جباري

j2017/2016 


\begin{tabular}{|c|c|c|c|c|c|c|c|c|}
\hline \multirow[t]{2}{*}{ الملاحظة } & \multicolumn{2}{|c|}{ بالنسبة للدرجات } & \multicolumn{2}{|c|}{ بالنسبة للمجال } & \multirow[t]{2}{*}{ التوصيف } & \multirow{2}{*}{ 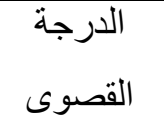 } & \multirow[t]{2}{*}{ المجالات } & \multirow[t]{2}{*}{ ت } \\
\hline & غير موافق & مو افق & غير صالحة & صالحة & & & & \\
\hline & & & & & لكل مادة ( 5 ) درجات & صفر - 5 & 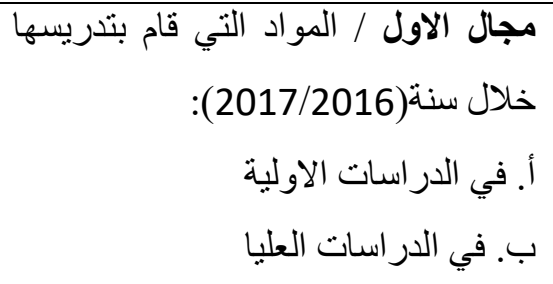 & 1 \\
\hline & & & & & 15 لكل مشروع تخرج للطلبة ( 5 ) درجات & صفر - صفر - 25 & بأ. الطلبة لعام الثاني / الاشر اف على بحوث & 2 \\
\hline & & & & & لكل كتاب ( 5 ) درجات المؤلف أو مترجم & صفر - 10 & لعام 2017/2016 لثال الثالث / تأليف كتاب أو ترجمة & 3 \\
\hline & & & & & لكل لكل بحث ( 15 لكل ) درجة 5 د د درجات & صفر - صفر - صفر - 10 & 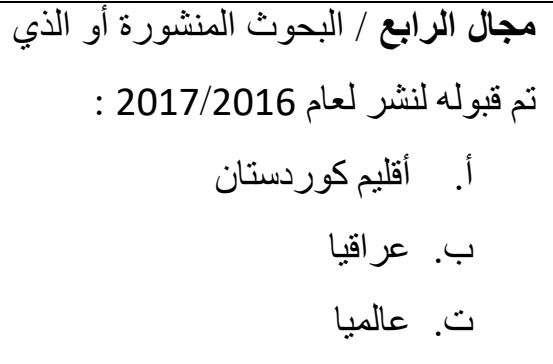 & 4 \\
\hline & & & & & لكل لكؤتمر ( 5 ) درجات & صفر - 10 & 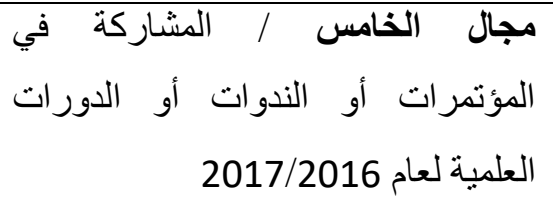 & 5 \\
\hline
\end{tabular}




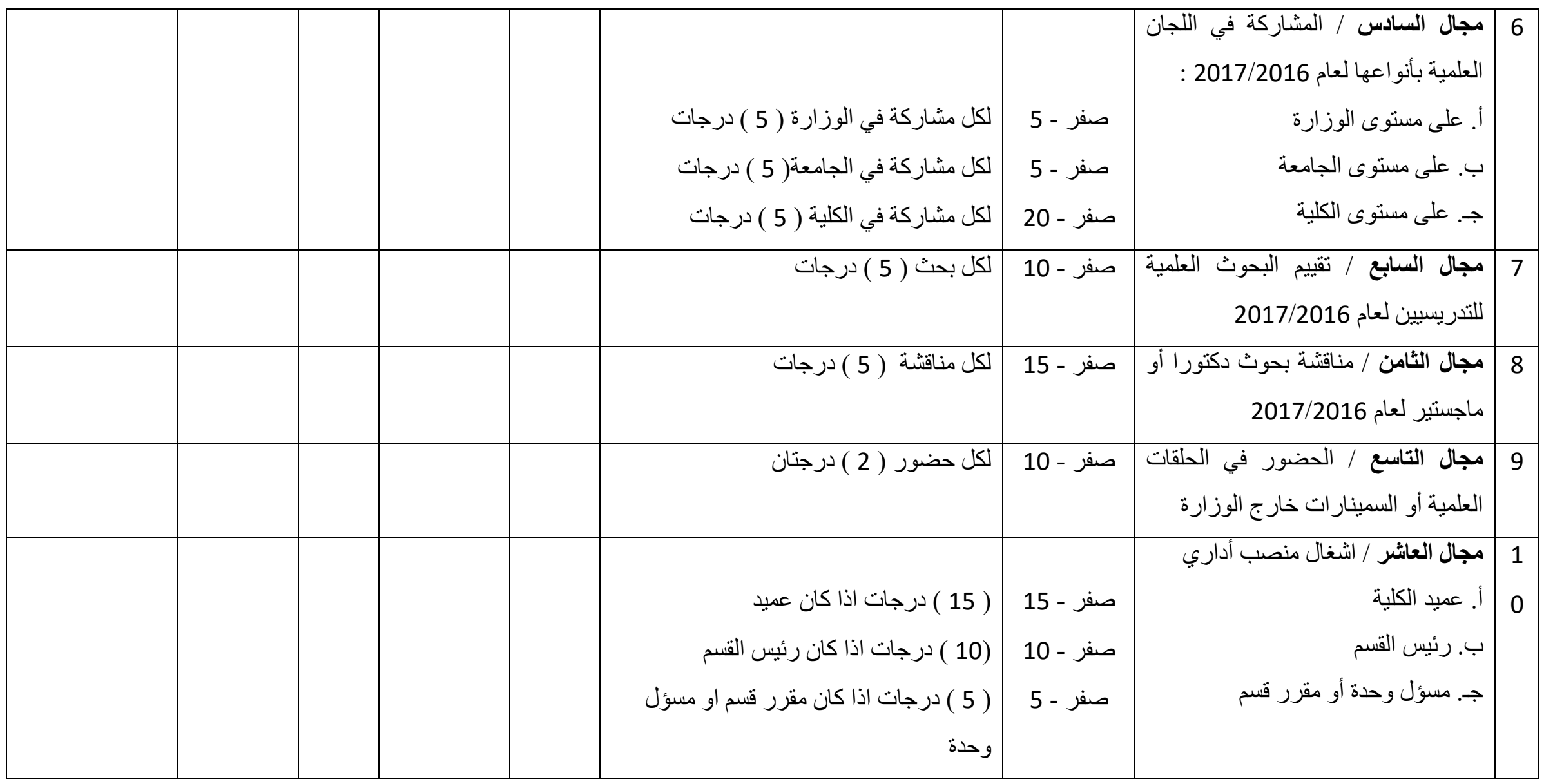


الملحق ( 2 )

يبيين أسماء السادة المحكمين و الخبراء لصدق المقياسين حسب المرتبة العلمية و الحروف الابجدية

\begin{tabular}{|c|c|c|c|}
\hline القسم و الكلية و الجامعة & الاسم الثلاثي & اللقب العلمي & $ت$ \\
\hline التربية - جامعة صلاح الدين - اربيل & بيريفان عبدالله محمد & أ. & 1 \\
\hline التربية و علم الفس - جامعة دهوك & صابر عبدلله سعيد زيباري & أ. د & 2 \\
\hline الاداب - جامعة صلاح الدين - اربيل & عمر ابر اهيم عزيز & أ. أ. & 3 \\
\hline التربية - جامعة صلاح الدين - اربيل & عمر ياسين ابر اهيم جبارى & أ. أد & 4 \\
\hline التربية الاساسية - جامعة السليمانية & كريم شريف قرضتانى & أ. د & 5 \\
\hline الاداب - جامعة بغداد & ياسين حميد عبدالرحمن & أ. أ.د & 6 \\
\hline التربية - جامعة كوية & بدرخان مصطفى ابر اهيم & أ. م. د & 7 \\
\hline التربية - جامعة طةرميان & حسين اسماعيل بك & أ. م. د & 8 \\
\hline التربية الاساسية - جامعة سليمانية & رشدي على ميرزة جاف & أ. م. د & 9 \\
\hline التربية و علم الفس - جامعة دهوك & ضاضنان جمعة محمد & أ. م. د & 10 \\
\hline التربية - جامعة كوية & كاوة على محمد & أ. م. د & 11 \\
\hline تربية و علم الفس - جامعة دهوك & محمد سعيد محمد & أ. م. د & 12 \\
\hline الاداب - جامعة صلاح الدين -اربيل & مها حسن بكر & أ. م. د & 13 \\
\hline التربية - جامعة صلاح الدين - اربيل & مؤيد اسماعيل جرجيس & أ. م. د & 14 \\
\hline التربية- جامعة صلاح الدين - اربيل & شَقوبؤ شمس الدين سليمان & د. & 15 \\
\hline علم النفس - التربية - جامعة طةرميان & وليد خالد بابان & د. & 16 \\
\hline
\end{tabular}

الملحق 3

المقياس التقويم الاداء بالصيغة النهائية 
بين يديكم مجمو عة من مجالات الاداء عن التدريس و النشاطات التي قمت بها خـلال سنة 2016-2017، يرجى منكم قر اءة كل مجال منها بإمعان والإجابة عنها ، علما بأن هذه البيانات هي لإنجاز رسـالة علميـة ولن تستخدم إلا لأغر اض البحت البحث العلمي لذا يرجو الباحث الإجابة عن المجالات جميعها دون ترك أية سؤال ، من خلال تحويل الاجابات الى ارقام. مع فائق الثكر و الامتنان... ملاحظة: قبل البدء بالإجابة يرجى منكم تدوين المعلومات الآتية:

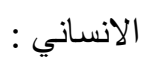
الاختصاص: العلمي :

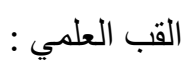


ب. بحوث ماجستير و دكتورا:

3. نأليف كتاب أو ترجمة لعام 2017/2016:

4. البحوث المنشورة أو الذي تم قبوله لنشر لعام 2017/2016 :

أ. أقليم كوردستان:

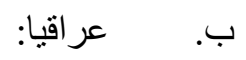

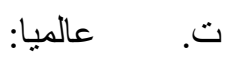

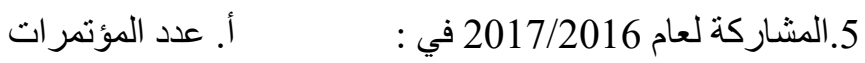

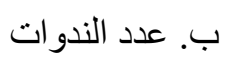

ج. عد الدور ات العلمية

6. المشاركة في اللجان العلمية بأنو اعها لعام 2017/2016 :

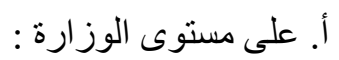

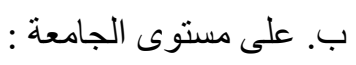

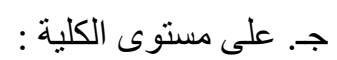

7. تقييم البحوث العلمية للتنريسيين لعام 2017/2016 :

| ا. بحوث دكتور ا

8.مناقشة لعام 2017/2016:

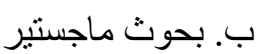

9.الحضور في الحلقات العلمية أو السمينار ات خارج الوزارة:

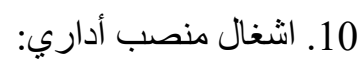

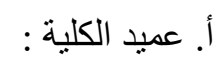

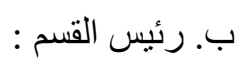

ج. مسؤل وحدة أو مقرر قسم :

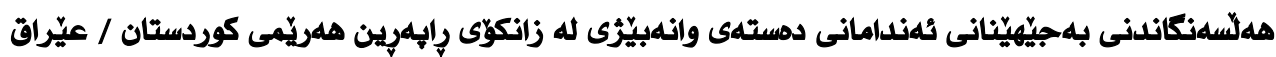

بوختهى تويَزَينهوه

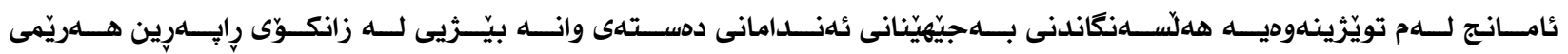

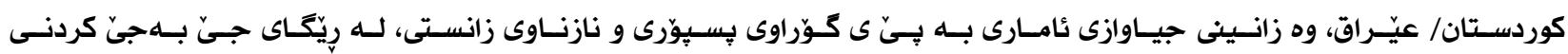
420

DOI: https://doi.org/10.26750/vol(6).no(1).paper19 http://journal.uor.edu.krd/index.php/JUR_ Vol. 6, No.1, June. 2019 


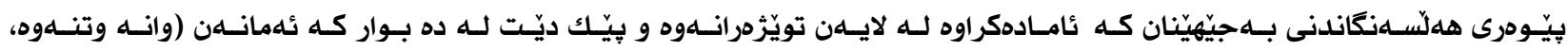

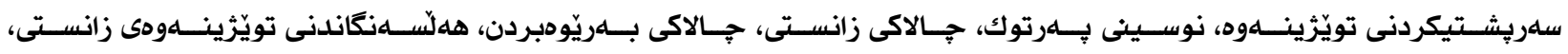

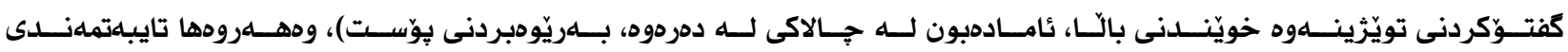

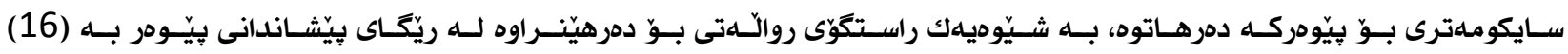

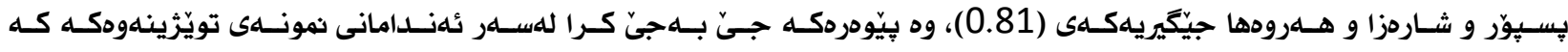

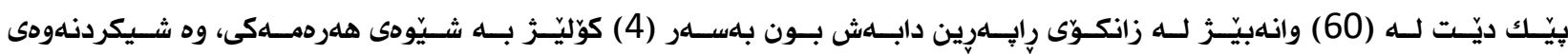
ئامارى ئهم يُهنجامانهى خواردوه دمردهخهن :

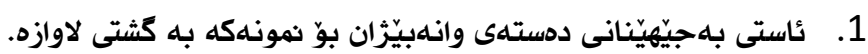

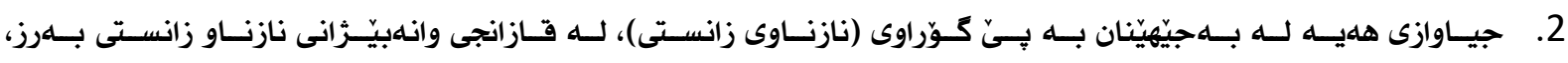

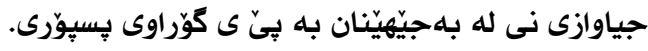

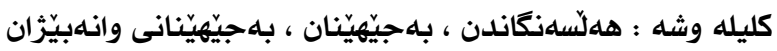

Title:

The evaluation of members in teaching board of Raparin University in Kurdistan RegionIraq

\section{Abstract}

This research aims to evaluate the members in teaching board of Raparin University in Kurdistan Region-Iraq and identifying the statistical differences according to variables specialty and academic title. The evaluation is via applying performance assessment scale which has been prepared by the researchers. The scale is consisted of 10 subscales as following (teaching, research supervising, writing books, research publications, scientific activities, administrative activities, evaluating scientific researches, higher education research discussions, attending outer activities and having an administrative position). The psychometric properties of the scale have been measured. Face validity 
has been conducted by showing the scale to 16 experts. Reliability was $(0,81)$. The scale was applied to a sample of (60) teachers that has been chosen randomly amongst 4 colleges of Raparin University.

After data processing, the results showed that:

1- The overall performance of the sample was poor.

2- There is a statistically significant difference according to scientific title in advantage of higher titles. And there are not any statistically significant differences according to scientific specialty.

Keyword: evaluation, performance, teaching performance 